\title{
Musculoskeletal biomechanics of patients with or without adjacent segment degeneration after spinal fusion
}

\author{
Mazda Farshad ${ }^{1 *}$, Pascal Raffael Furrer ${ }^{1}$, Florian Wanivenhaus ${ }^{1}$, Lukas Urbanschitz ${ }^{1}$ and Marco Senteler ${ }^{1,2}$
}

\begin{abstract}
Study design: A retrospective, single center, case-control study was performed.

Objective: The present study employed patient-specific biomechanical modeling to find potential biomechanical differences after spinal fusion at $L 4 / 5$ in patients with and without subsequent development of adjacent segment disease (ASD).

Methods: The study population comprised patients who underwent primary spinal fusion at $L 4 / 5$ and were either asymptomatic during $>4$ years of follow-up (CTRL; $n=18)$ or underwent revision surgery for ASD at L3/4 $(n=20)$. Landmarks were annotated on preoperative and follow-up lateral radiographs, and specific musculoskeletal models were created using a custom-built modeling pipeline. Simulated spinal muscle activation and lumbar intervertebral shear loads in unfused segments were analyzed in upright standing and forward flexion. Differences between the pre- and postoperative conditions were computed for each patient.

Results: The average postoperative muscle activity in the upright standing posture was $88.4 \%$ of the preoperative activity in the CTRL group $(p<0.0001)$, but did not significantly change from pre- to postoperatively in the ASD group (98.0\%). The average shear load magnitude at the epifusional joint L3/4 during upright standing increased from preto postoperatively in the ASD group $(+3.9 \mathrm{~N},+/-17.4(n=18))$, but decreased in the CTRL group $(-4.6 \mathrm{~N},+/-23.3$ $(n=20) ; p<0.001)$.

Conclusion: Patient-specific biomechanical simulation revealed that spinal fusion surgery resulted in greater shear load magnitude and muscle activation and therefore greater forces at the epifusional segment in those with ASD compared with those without ASD. This is a first report of patient-specific disc load and muscle force calculation with predictive merits for ASD.
\end{abstract}

Keywords: Adjacent segment disease, Spinal fusion, Biomechanical modeling, Patient-specific biomechanical simulation, Preoperative planning, Sagittal alignment

\section{Introduction}

Adjacent segment disease (ASD) is a major complication of spinal fusion surgery, with a reported incidence of $37.4 \%$ within 5 to 20 years postoperatively [1]. Numerous

\footnotetext{
*Correspondence: mazda.farshad@balgrist.ch

1 Department of Orthopaedics, Balgrist University Hospital, University of Zurich, Forchstrasse 340, 8008 Zurich, Switzerland
}

Full list of author information is available at the end of the article studies have identified potential risk factors for ASD, such as age, sex, osteoporosis, number of fused segments, and laminectomy at the segment adjacent to fusion [2-4]. Most of such potential risk factors are not modifiable and failed to fully explain the occurrence of ASD. However, biomechanical consequences of spinal fusion, even if potentially modifiable, are currently not sufficiently considered as powerful contributors to ASD. Some cadaveric original author(s) and the source, provide a link to the Creative Commons licence, and indicate if changes were made. The images or other third party material in this article are included in the article's Creative Commons licence, unless indicated otherwise in a credit line to the material. If material is not included in the article's Creative Commons licence and your intended use is not permitted by statutory regulation or exceeds the permitted use, you will need to obtain permission directly from the copyright holder. To view a copy of this licence, visit http://creativecommons.org/licenses/by/4.0/. The Creative Commons Public Domain Dedication waiver (http://creativeco mmons.org/publicdomain/zero/1.0/) applies to the data made available in this article, unless otherwise stated in a credit line to the data. 
studies have shown an increase in the forces and range of motion at the adjacent intervertebral joint $[5,6]$. Other biomechanical consequences include the amount of stress on the adjacent disc [7], sagittal balance [8-10], pelvic parameters [11], and the amount of postoperative lumbar lordosis [12]. These biomechanical consequences of spinal fusion are identified indeed, yet not used on a patient-specific level to prove their potential contribution to ASD.

We aimed to investigate whether biomechanical changes in the lower lumbosacral region, which account for $66 \%$ of the lumbar lordosis on average [13], affect the development of ASD using a patient-specific biomechanical modeling approach. We chose to compare patients who underwent revision surgery for ASD after L4/5 single-level spinal fusion to a control group of patients without ASD after L4/5 single-level spinal fusion (CTRL group). We hypothesized that the effect of fusion surgery on musculoskeletal loads differs between CTRL and ASD patients. If so, this would imply that the risk of ASD could be determined and modified preoperatively by patient-specific musculoskeletal analyses of biomechanical consequences of spinal fusion on muscle activity and joint loads.

\section{Materials and methods \\ Patients}

The present study was a retrospective, single center, casecontrol study. Included were patients that underwent a primary standard open single-level spinal fusion of the L4/5 segment. All patients were initially operated on or received revision surgery at a single University Spine Center. Patients who developed degeneration and underwent revision surgery at the proximal adjacent segment L3/4 (ASD group) were compared with a cohort of control patients who did not develop postoperative degenerative changes at a minimum of 4 years follow-up (CTRL group). Excluded were patients with insufficient quality of X-ray, meaning not showing both femoral heads, the sacral tip and at least the T12 vertebra. All of these landmarks were needed for the simulation. Furthermore, spondylolisthesis of grade 2 or higher was an exclusion criteria imposed by limitations of biomechanical simulations. Additional exclusions for the control group was an insufficient outcome at follow up, which was defined by local lumbar or radiating pain. The preoperative degeneration of the adjacent segment was measured on MRIs with the Pfirrmann [14] and Weishaupt [15] classification.

\section{Modeling and simulation}

To determine the muscular activity and joint loads in the ASD and CTRL groups, an OpenSim (v.4.0, simtk. org [16]) musculoskeletal model was created for each included patient in the pre- and postoperative conditions. Patient-specific modeling was based on an established internal modeling workflow that has been described previously in detail [17]. Modeling included modification of a generic template model based on annotated landmarks on a lateral $x$-ray. The generic model represents a full body model with an articulated lumbar spine and nonlinear lumbar intervertebral stiffness properties, featuring 216 muscle fascicles for the upper body and spinal articulation. A detailed description of the template model has been published previously [18].

The subsequent modeling process [11] was based on $\mathrm{x}$-rays showing the following landmarks: The base- and endplate edges of the vertebrae from L 5 to T12, the endplate of the sacrum and sacrum tip, and both femoral heads to obtain the midpoint of the bicoxofemoral axis (Fig. 1).

Annotations were made by two trained orthopedic surgeons on the original $x$-ray using a custom-built annotation tool in MATLAB (R2016b, The MathWorks, MA, USA) compiled into a standalone application. A previous evaluation of inter-rater reliability showed that the determination of vertebral body centers has an average agreement within $4.6 \%$ of vertebral body height (normalized bias), and the slope of a segment has an average agreement of within $0.4^{\circ}$. As the pre- and postoperative images were annotated by the same person, the intra-rater agreement was also quantified, giving average values of $3.1 \%$ for the vertebral body height and $<0.1^{\circ}$ for the segmental slope.

Each patient was simulated in the pre- and postoperative conditions in two static postures: upright standing and $30^{\circ}$ forward flexion. The simulation itself represented a standard OpenSim workflow consisting of Static Optimization and Joint Reaction Analysis. The Static Optimization resolved the enforced posture into net joint moments and further into required muscle activation. The objective function for muscle activation was minimization of the overall sum of the squared muscle activation, and was comparable with minimizing the energy expenditure. The Joint Reaction Analysis computed the loads acting in the intervertebral joints. The computed joint loads were output as components of shear and compression. The simplification of models built on sagittal symmetry implies negligible lateral shear forces; consequently, only posterior-anterior shear and axial compression forces were assessed in the present study. (Fig. 2).

\section{Statistics}

Postoperative muscle activity was normalized to preoperative muscle activity by $100 \%$. A non-parametric 


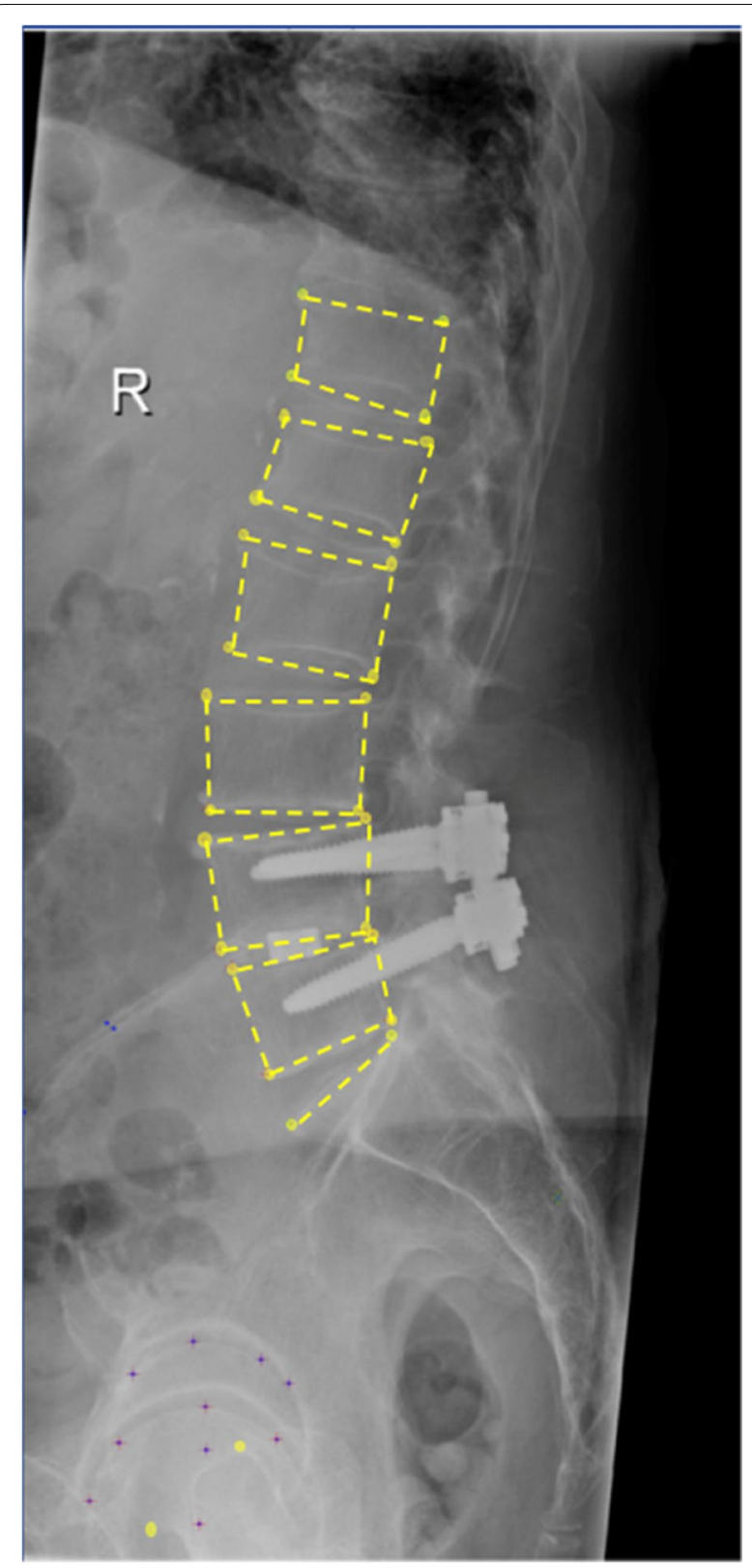

Fig. 1 Annotation of the femoral heads, sacral endplate, and vertebral bodies on a lateral $\mathrm{x}$-ray of a patient who had undergone L4/5 spinal fusion paired test (one-sample Wilcoxon) was performed to test for intragroup differences between pre- and postoperative muscle activation. A non-parametric unpaired test (Kolmogorov-Smirnov) was performed to test for differences between the ASD and CTRL groups. Epifusional classification crosstable was calculated with fisher's exact test. Data is presented as mean \pm standard deviation. The level of significance was set to $p<0.05$.

\section{Results}

Patients

The ASD group contained 20 patients, from 2004 to 2017. The mean time between the first surgery and the revision was 46 months (44-181). The CTRL group contained 18 patients, from 2004 to 2015 .

There was no difference in age between the groups, $65.7 \pm 8.0$ years in the ASD group and $60.6 \pm 13.2$ years in the CTRL group $(p=0.154)$. Neither has a difference been seen in the body mass index between the two groups (Table 1). Most importantly, no difference in epifusional degeneration was seen on preoperative MRIs (Pfirrmann $p=0.717$, Weishaupt $P=0.212$ ) which were taken 1.7 months $( \pm 2.0)$ before the operation. Thirtyseven (97\%) MRIs were analyzed, one (3\%) was not available for review.

\section{Conventional measurement of spinopelvic parameters}

The measured standard spinopelvic parameters (pelvic incidence, lumbar lordosis, sacral slope, pelvic tilt, pelvic incidence - lumbar lordosis mismatch) did not significantly differ between the two groups. Deviations from the calculated ideal pelvic tilt as described by Vialle et al. [19] were not significantly different between the ASD and CTRL group (Table 2).

\section{Muscular activity}

The CTRL group showed a significant reduction in total muscle activity from preoperatively to postoperatively in both postures; the average postoperative muscle activity was $88.4 \%$ of the preoperative activity in the upright standing posture $(p<0.0001)$ and $93.6 \%$ of the preoperative activity in $30^{\circ}$ forward flexion $(p=0.016)$. In contrast, the total muscle activity in the ASD group did not significantly change from pre- to postoperatively in the upright standing posture $(98.0 \%)$ or the forward flexed posture (99\%) (Fig. 3, Table 3).

There was no significant change from pre- to postoperatively in the muscle activity of any of the individual major muscle groups. Furthermore, their activity did not significantly differ between the CTRL and ASD groups. When the muscle groups were further distinguished by anatomical locations, the activity of the multifidi muscles that attach at the fused vertebra (L4) was significantly greater in the ASD group than the CTRL group.

\section{Joint loads}

The average joint shear loads in both the CTRL and the ASD groups differed moderately between the pre- and postoperative conditions. The forces significantly differed between the pre- and postoperative conditions in 


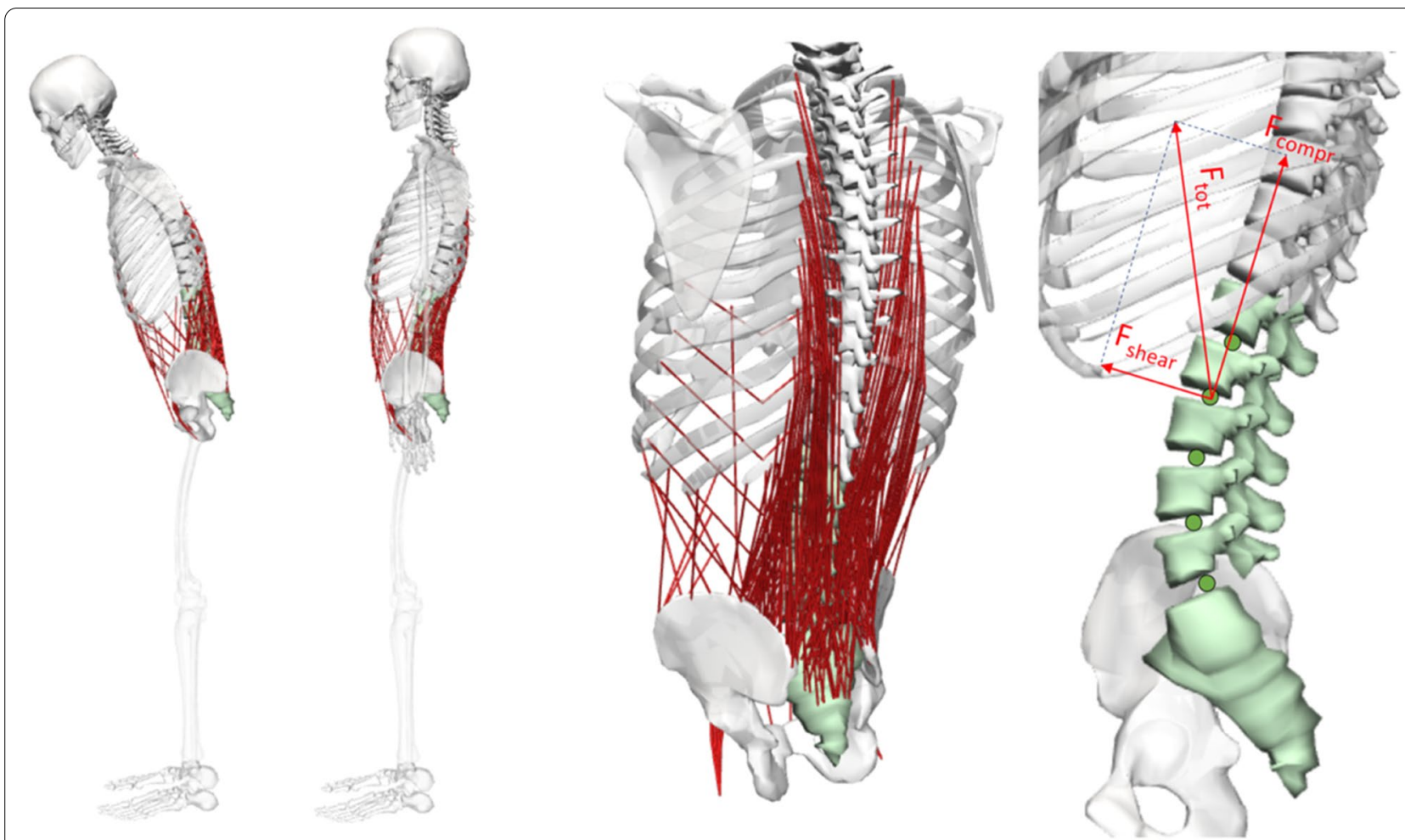

Fig. 2 An example of our patient specific musculoskeletal model with the two postures upright and $30^{\circ}$ foreward flexion (left). The whole trunk and the spinopelvic system with a detailed representation of the simulated musculoskeletal situation (middle). Calculated spinal forces compression and shear (right)

Table 1 Patients demographics: Data are presented as mean \pm standard deviation. ASD group: patients who underwent revision surgery for adjacent segment disease after spinal fusion; CTRL group: patients without adjacent segment disease after spinal fusion

\begin{tabular}{llll}
\hline Variable & ASD & CTRL & P value \\
\hline No. of patients & 20 & 18 & \\
Age (years) & $65.7 \pm 8.0$ & $60.6 \pm 13.2$ & 0.154 \\
Female sex (\%) & 65 & 50 & 0.363 \\
Body mass index $\left(\mathrm{kg} / \mathrm{m}^{2}\right)$ & $26.3 \pm 3.8$ & $26.6 \pm 5.0$ & 0.877 \\
\hline
\end{tabular}

both groups at T12/L1 in the upright posture $(p<0.05)$ and at L3/4 in the flexed posture $(p<0.0001)$, as well as in the CTRL group at L2/3 in the flexed posture $(p<0.01)$ (Table 4).

The average shear loads in the ASD group tended to be slightly larger than those in the CTRL group. However, significant differences were only detected between the groups in the forces at L5/S1 during upright standing in both the pre- and postoperative conditions ( $p=0.024$ and $p=0.026$, respectively).
When the changes in shear load magnitudes from the pre- to postoperative condition were considered on a patient-by-patient basis, the effect of fusion on shear loads was similar in both the CTRL and ASD groups. (Fig. 4).

However, opposing trends were observed at the epifusional joint L3/4, which experienced a postoperative increase in shear load magnitude in the ASD group during upright standing $(+3.9 \mathrm{~N})$ and a postoperative decrease in the CTRL group $(-4.6 \mathrm{~N})$ (Fig. 5). Similarly, the force at L5/S1 slightly increased from pre- to postoperatively in the ASD group during flexion $(+2.0 \mathrm{~N})$, but decreased from pre- to postoperatively in the CTRL group $(-8.7 \mathrm{~N})$. However, although the average reduction in shear force magnitude was larger in the CTRL group than in the ASD group, these pre- to postoperative differences were not significant in either group.

\section{Discussion}

Among many potential factors influencing the development of ASD, biomechanical factors are modifiable by the surgeon, however yet not fully understood. Patientspecific musculoskeletal analyses of biomechanical consequences of spinal fusion could have predictive merits 
Table 2 Pre- and postoperative spinopelvic parameters: Data are presented as mean \pm standard deviation

\begin{tabular}{|c|c|c|c|c|c|c|}
\hline \multirow[b]{2}{*}{ Variable } & \multicolumn{3}{|c|}{ Preoperative } & \multicolumn{3}{|c|}{ Postoperative } \\
\hline & ASD & CTRL & $P$ value & ASD & CTRL & $P$ value \\
\hline Pelvis incidence $\left({ }^{\circ}\right)$ & $51.7 \pm 7.6$ & $51.6 \pm 11.0$ & 0.986 & $54.1 \pm 8.4$ & $51.7 \pm 12.1$ & 0.499 \\
\hline Pelvic tilt $\left(^{\circ}\right)$ & $17.0 \pm 5.4$ & $19.7 \pm 7.9$ & 0.222 & $19.6 \pm 5.9$ & $20.9 \pm 8.2$ & 0.605 \\
\hline Sacral slope $\left(^{\circ}\right)$ & $34.1 \pm 6.4$ & $31.2 \pm 7.4$ & 0.198 & $33.7 \pm 7.0$ & $30.9 \pm 6.25$ & 0.164 \\
\hline Lumbar lordosis $\left({ }^{\circ}\right)$ & $52.0 \pm 9.5$ & $47.1 \pm 11.1$ & 0.151 & $50.2 \pm 10.3$ & $45.2 \pm 8.5$ & 0.109 \\
\hline$\triangle \mathrm{PI}-\mathrm{LL}$ & $-0.3 \pm 8.9$ & $4.6 \pm 9.8$ & 0.120 & $3.9 \pm 9.1$ & $6.5 \pm 9.6$ & 0.382 \\
\hline PTi & $12.1 \pm 2.8$ & $12.1 \pm 3.9$ & 0.986 & $13.9 \pm 3.1$ & $12.1 \pm 4.5$ & 0.490 \\
\hline$\triangle \mathrm{PTi}-\mathrm{PT}$ & $4.9 \pm 4.9$ & $7.6 \pm 5.4$ & 0.110 & $6.6 \pm 5.1$ & $8.7 \pm 4.8$ & 0.200 \\
\hline
\end{tabular}

$A S D$ adjacent segment disease, CTRL control group, $\triangle P I$-LL pelvic incidence-lumbar lordosis mismatch, $P T i$ ideal calculated pelvic tilt, $\triangle P T i-P T$ ideal pelvic tilt - pelvic tilt mismatch

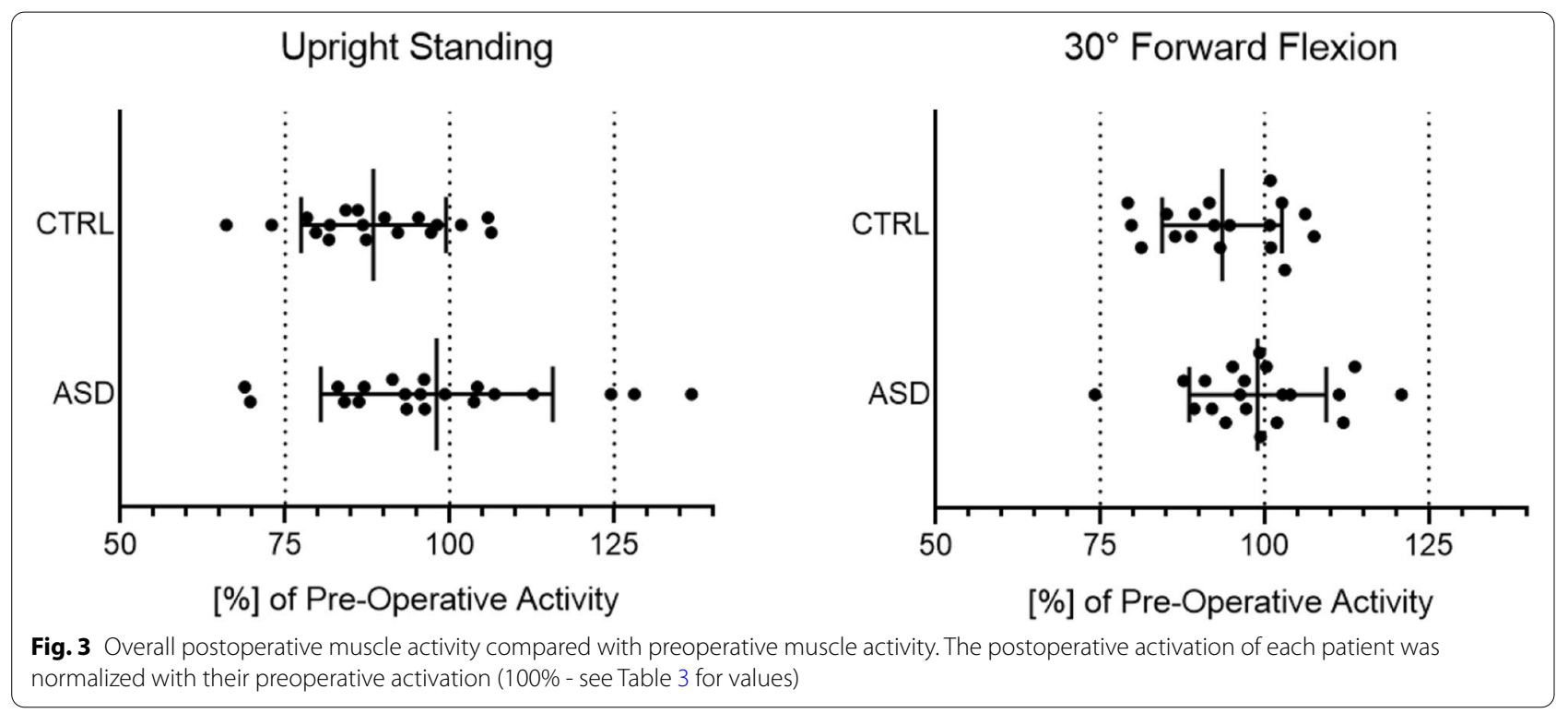

towards development of ASD and modify clinical decision making and surgical planning. Comparing the biomechanical effects of fusion on a patient-specific level allowed us to reveal important differences of patients with ASD versus without.

This concept is in concordance with several other studies that have shown that spinal fusion may result in an increase in motion and forces in the epifusional segment $[5,6,20]$ based on cadaveric or finite element investigations. Abode-Iyamah et al. found significant increasing disc pressure in the adjacent segment in a cadaveric study of nine specimens after lumbar spinal fusion [21]. Forces reported in such studies often rely on intradiscal pressure measurements, which are known to correlate with compressive loads in the discs. However, shear is an important loading mode in the context of onset and progression of disc degeneration [22, 23]. The loading of intervertebral segments in general is predominantly a result of body weight and active force contribution due to muscular activity. The separation of overall loads into shear and compressive load components are mainly a result of the orientation of the disc, and thus dependent on segmental kinematics during body movement. While cadaveric studies and most finite element studies do not assess the active load contribution of muscles, musculoskeletal modeling and simulation is capable of integrating muscle forces into analyses $[17,18,24]$. Therefore, the present study used the approach of patient-specific musculoskeletal analysis to address the hypothesis that muscular activity and intervertebral loading in patients with ASD differ from those in asymptomatic controls.

In the present study, two very homogenous groups were compared, initially having the same level fusion, the same demographic factors and did not show any difference in pre- and postoperative spinopelvic parameters nor in the Roussouly classification. The here demonstrated results confirmed the hypothesis that the asymptomatic CTRL group had less total activity of the 
Table 3 Muscle activation in the upright standing (Upright) and $30^{\circ}$ upper body forward flexed (Flexed) postures

\begin{tabular}{|c|c|c|c|c|c|c|}
\hline & & & Upright & & Flexed & \\
\hline & & & Preop & Postop & Preop & Postop \\
\hline CTRL group & Absolute activation & Mean & 5.30 & $4.66^{*}$ & 8.90 & 8.26 \\
\hline & & Range & {$[3.6-8.1]$} & {$[3.1-8.5]$} & {$[6.8-12.2]$} & {$[6.5-12.1]$} \\
\hline & & STD & 1.32 & 1.28 & 1.56 & 1.24 \\
\hline & & P & - & $<0.001$ & - & 0.020 \\
\hline & Activation normalized to preop & Mean & $100 \%$ & $88.4 \% *$ & $100 \%$ & $93.6 \%$ \\
\hline & & Range & - & {$[66-106]$} & - & [79-108] \\
\hline & & STD & - & $11 \%$ & - & $9.1 \%$ \\
\hline & & P & - & $<0.001$ & - & 0.016 \\
\hline ASD group & Absolute activation & Mean & 5.39 & 5.19 & 8.53 & 8.37 \\
\hline & & Range & {$[3.7-8.4]$} & {$[3.7-9.4]$} & {$[6.3-12.8]$} & {$[6.7-12.2]$} \\
\hline & & STD & 1.26 & 1.18 & 1.60 & 1.36 \\
\hline & & P & & 0.290 & - & 0.528 \\
\hline & Activation normalized to preop & Mean & $100 \%$ & $98.0 \%$ & $100 \%$ & $99.0 \%$ \\
\hline & & Range & - & {$[69-137]$} & - & [74-121] \\
\hline & & STD & - & $17.6 \%$ & - & $10.4 \%$ \\
\hline & & $P$ & - & 0.368 & - & 0.522 \\
\hline
\end{tabular}

Table 4 Shear forces in the pre- and postoperative conditions for the upright standing posture (left) and forward flexed posture (right) (Fig. 3). $P$ values for non-parametric paired test between pre- and postoperative values (Wilcoxon matched-pairs signed rank). $\Delta$ (abs) is the group average of the difference in shear force magnitude between the pre- and postoperative conditions (Fig. 4)

\begin{tabular}{|c|c|c|c|c|c|c|c|c|c|}
\hline \multirow[t]{2}{*}{ SHEAR } & & \multicolumn{4}{|c|}{ Upright standing posture } & \multicolumn{4}{|c|}{$30^{\circ}$ forward flexion posture } \\
\hline & & preop $[N]$ & postop $[\mathrm{N}]$ & $\mathrm{p}$ & $\Delta(\mathrm{abs})$ & preop $[\mathrm{N}]$ & postop $[\mathrm{N}]$ & $p$ & $\Delta(\mathrm{abs})$ \\
\hline \multirow[t]{5}{*}{ CTRL group } & $\mathrm{T} 12 / \mathrm{L} 1$ & -145 & -116 & 0.021 & -29.0 & -63 & -49 & 0.284 & -7.7 \\
\hline & $\mathrm{L} 1 / 2$ & -89 & -76 & 0.196 & -12.5 & -29 & -26 & 0.966 & -0.1 \\
\hline & $\mathrm{L} 2 / 3$ & -34 & -32 & 0.551 & -2.6 & 48 & 32 & 0.004 & -8.1 \\
\hline & $\mathrm{L} 3 / 4$ & 30 & 34 & 0.417 & -4.6 & 76 & 37 & $<0.0001$ & -38.4 \\
\hline & L5/S1 & 309 & 302 & 0.610 & -6.9 & 401 & 403 & 0.966 & -8.7 \\
\hline \multirow[t]{5}{*}{ ASD group } & $\mathrm{T} 12 / \mathrm{L} 1$ & -180 & -155 & 0.044 & -24.4 & -93 & -78 & 0.430 & -8.0 \\
\hline & $\mathrm{L} 1 / 2$ & -101 & -90 & 0.246 & -9.5 & -37 & -31 & 0.870 & -11.7 \\
\hline & $L 2 / 3$ & -41 & -36 & 0.498 & -4.9 & 43 & 32 & 0.064 & -11.6 \\
\hline & $\llcorner 3 / 4$ & 39 & 44 & 0.246 & +3.9 & 90 & 49 & $<0.0001$ & -39.5 \\
\hline & $L 5 / S 1$ & 356 & 348 & 0.189 & -8.6 & 445 & 436 & 0.409 & +2.0 \\
\hline
\end{tabular}

core- and paraspinal muscles after L4/5 spinal fusion compared with the activity prior to fusion. In contrast, the ASD group demonstrated unchanged muscular activity. As the loading of intervertebral joints largely depends on muscular activity, these results also suggest the presence of larger and potentially adverse loading in patients who developed ASD. The increased postoperative muscle activity in the ASD group as compared to the CTRL group during upright standing may also be explained by a less balanced upper body posture in the ASD group, which requires higher muscle forces to maintain equilibration. Therefore, as expected, the ASD group also had greater compressive forces in the upright standing posture as compared to the CTRL group. The finding of this simulation may be used in preoperative planning to find the best possible sagittal alignment for every patient in order to have the least amount of muscle activity and compression forces after surgery. Hence, the presented method offers a possibility to surgeons to preoperatively simulate and calculate the optimal fusion parameters for each patient, in order to achieve lower loadings and reducing the risk of ASD. Excitingly, 


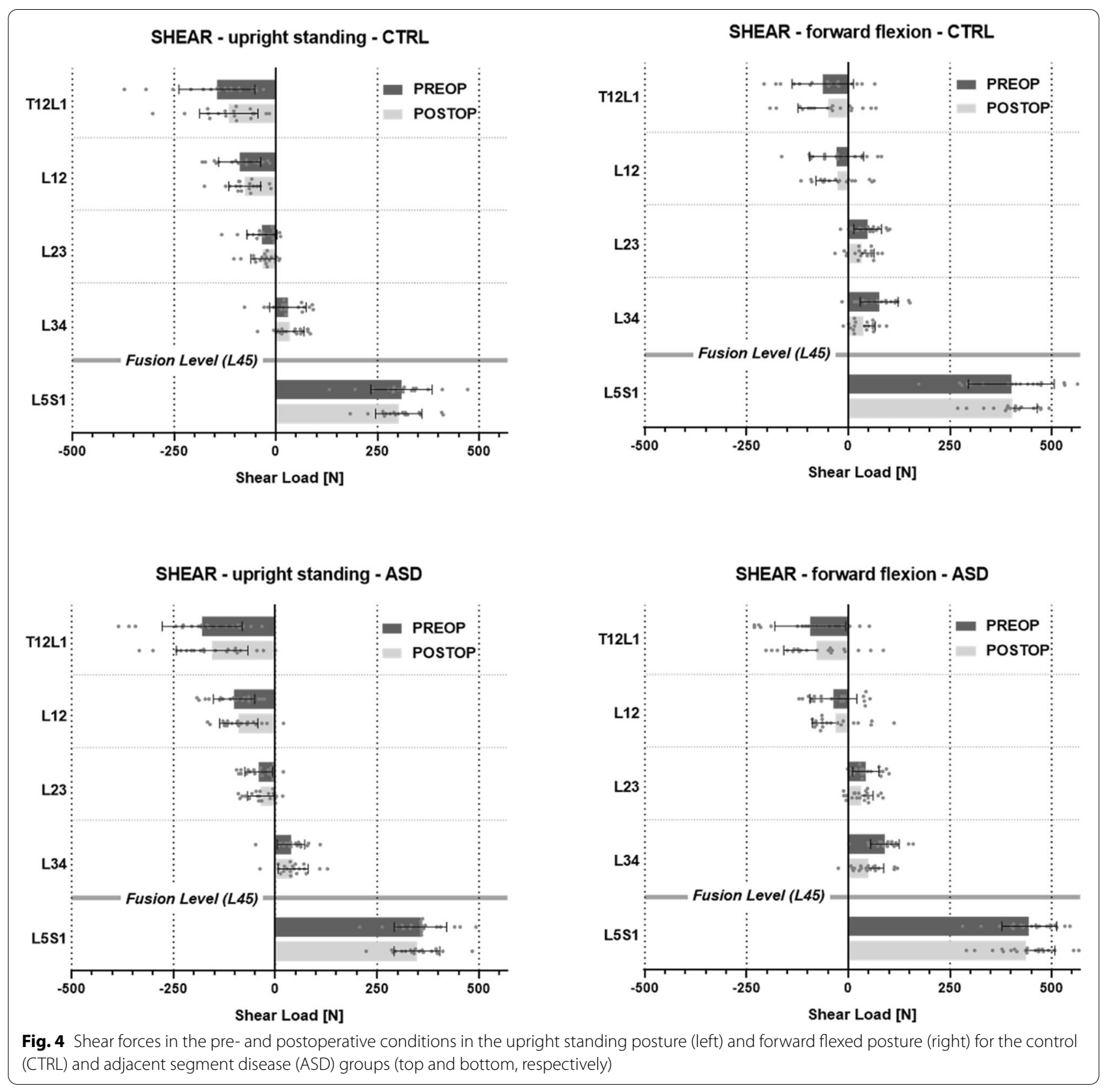

a difference between the two groups was seen in our biomechanical analysis, which could not be seen with the established conventional spinopelvic parameters. Thus, a more accurate and precise preoperative planning might be made with the presented simulation as compared to the conventional preoperative planning currently used for the majority of surgical planning.

As with any patient-specific simulation study, the modeling process was governed by simplifications and assumptions. General limitations are presented and discussed in detail in previous publications [17, 24].
The following specific limitations were identified for the present cohort study: First, the muscle properties and body masses could not be fully individualized. Although this means that the models were less personalized, this method was justified because it enabled the comparison of results between patients and groups without normalization. Also, the spinopelvic anatomy, which is considered the major risk factor for ASD, was specifically represented in all models. It was individualized based on lateral X-rays, with the inherent blurring of the beam path. The projection angle 

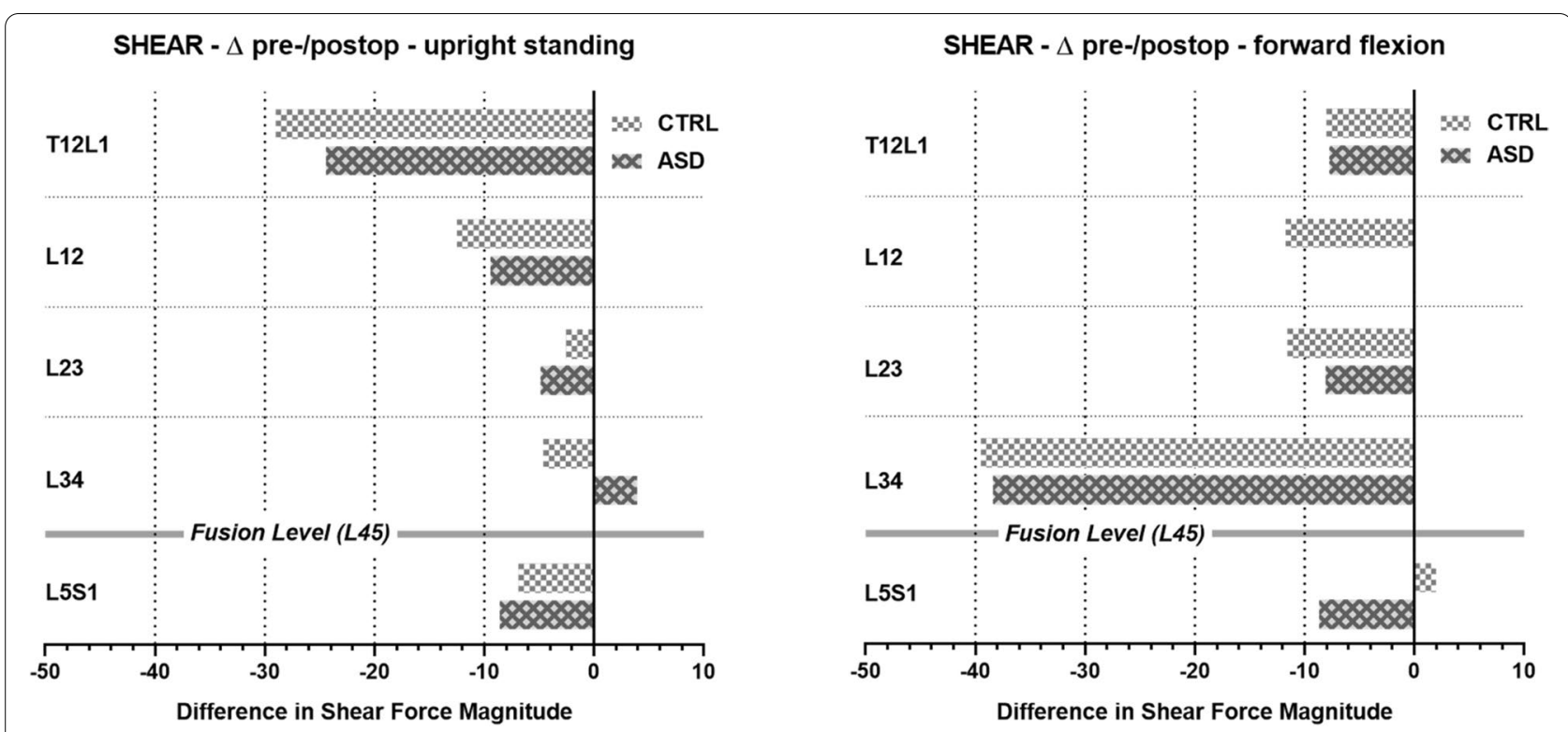

Fig. 5 Average difference in shear force magnitude between the pre- and postoperative conditions. The pairs of bars represent the control (CTRL; light grey, top) and adjacent segment disease (ASD; dark grey, bottom) groups

of the spinopelvic system was adjusted and the beam magnification balanced by the bicoxofemoral axis. After adjustment, the effects of X-ray imaging on spinal alignment were considered minimal. On the contrary, conventional radiographs had a remarkable advantage over other imaging modalities such as CTs: the standing posture of the patients. This is more representative to loading scenarios in daily living, as well as more accurate for the assessment of spinopelvic alignment, thus better justifying comparison to the existing literature. Second, the assumed segmental kinematics for obtaining the flexed postures were generic, and therefore the simulated slope angles of intervertebral discs in the flexed posture may have deviated from reality. Although this is not particularly relevant for muscle activity and total joint loads, it affects the breakdown of loads into shear and compression. Despite recent efforts to successfully quantify the motion of vertebrae in vivo [25], there is currently no method allowing continuous and systematic assessment of spinal kinematics. Consequently, it is necessary to use a generally assumed spinal kinematic rhythm when simulating postures for which no radiological data exist. Third, given the variability of anatomy and conditions of spinal fusion patients in combination with the multifactorial pathogenesis of ASD, the patient population included in the present retrospective study was fairly limited. Future investigations including other singleand multi-level fusions as well as prospective studies are likely to provide even clearer separations between groups. And last, the degeneration of the adjacent segments was not taken into consideration with this simulation, yet we know about the change of forces with the increasing degeneration of a segment [26]. But since the patients of the two groups did not have a difference between the preoperative degeneration of the adjacent segment this factor might in our case be neglected.

The differences of the forces between the groups were in many measures very small. One can imagine that these parameters gain significance with increased body weight, especially around the waist and trunk as well as with more physical work. These may also be risk factors and influence the occurrence of an ASD but in our case had no significant difference between the groups. The total muscle activation is also a sign of a worse osseous balance, which is reinforced with additional body weight and with physically demanding work.

The study limitations explain, to some extent, the clearer separation between the present ASD and CTRL groups for muscle loads than for joint loads. The muscle activity is mainly a direct result of the posture and anatomy. In contrast, the shear and compression components depend on the muscle activity, as well as on the anatomy and kinematics. The high sensitivity of load components to disc orientations, which are modeled with limited accuracy, may thus reduce the intergroup differences in shear forces. 


\section{Conclusion}

The current study showed that in patients with ASD at L3/4, the L4/5 lumbar spinal fusion did not increase the overall muscle activity. In contrast, patients who had undergone spinal fusion at L4/5 and had not developed ASD after a minimum 4 years of follow-up showed a significant reduction in overall muscle activity compared with preoperatively. The present results therefore provide the basis for future studies aiming for a prognostic biomechanical evaluation of the risk of ASD in patients undergoing spinal fusion surgery. Geometrical planning, being currently the standard of surgical planning, neglects the emerging possibilities of considering biomechanical and kinematic information in a patientspecific way. A change of paradigm in evaluation of risk of ASD on a patient specific level using musculoskeletal biomechanical planning is described here and should introduce further research and development towards the next level of surgical planning.

\section{Acknowledgments}

This work is part of the SURGENT project under the umbrella of University Medicine Zurich / Hochschulmedizin Zürich.

We also thank Kelly Zammit, BVSc, from Edanz Editing, for editing a draft of this manuscript.

\section{Authors' contributions}

M.F. and M.S. conceived of the presented idea. P.F., F.W. and L.U. developed the theory and did the data collection. M.S. performed the computer model simulation and the statistical analysis. All authors discussed the results and contributed to the final manuscript. All authors reviewed the manuscript. The author(s) read and approved the final manuscript.

\section{Funding}

No funding for this project.

\section{Availability of data and materials}

The datasets used and/or analyzed during the current study are available from the corresponding author on reasonable request.

\section{Declarations}

\section{Ethics approval and consent to participate}

All procedures performed in studies involving human participants were in accordance with the ethical standards of the institutional and national research committee and with the 1964 Helsinki declaration and its later amendments or comparable ethical standards. Approval from our local ethic committee (Kantonale Ethikkommission Zürich) was given with the reference number: 2018-00058. Informed consent was obtained from all individual participants included in the study.

\section{Consent for publication}

Not applicable.

\section{Competing interests}

The authors disclose ties to Prognosyst AG, Zurich, Switzerland, which is developing solutions for the preoperative planning of spinal surgeries. M.F. was shareholder and member of the boards. The others have no competing interests.

\section{Author details}

'Department of Orthopaedics, Balgrist University Hospital, University of Zurich, Forchstrasse 340, 8008 Zurich, Switzerland. ${ }^{2}$ Institute for Biomechanics, ETH Zürich, Leopold-Ruzicka-Weg 4, 8093 Zurich, Switzerland.
Received: 24 July 2021 Accepted: 22 November 2021

Published online: 13 December 2021

\section{References}

1. Xia XP, Chen HL, Cheng HB. Prevalence of adjacent segment degeneration after spine surgery: a systematic review and meta-analysis. Spine (Phila Pa 1976). 2013;38:597-608. https://doi.org/10.1097/BRS.0b013 e318273a2ea.

2. Park P, Garton HJ, Gala VC, Hoff JT, McGillicuddy JE. Adjacent segment disease after lumbar or lumbosacral fusion: review of the literature. Spine (Phila Pa 1976). 2004;29:1938-44.

3. Min JH, Jang JS, Jung B, Lee HY, Choi WC, Shim CS, et al. The clinical characteristics and risk factors for the adjacent segment degeneration in instrumented lumbar fusion. J Spinal Disord Tech. 2008;21:305-9. https:// doi.org/10.1097/BSD.0b013e318142b960.

4. Sears WR, Sergides IG, Kazemi N, Smith M, White GJ, Osburg B. Incidence and prevalence of surgery at segments adjacent to a previous posterior lumbar arthrodesis. Spine J. 2011;11:11-20. https://doi.org/10.1016/j. spinee.2010.09.026

5. Cunningham BW, Kotani Y, McNulty PS, Cappuccino A, McAfee PC. The effect of spinal destabilization and instrumentation on lumbar intradiscal pressure: an in vitro biomechanical analysis. Spine (Phila Pa 1976). 1997;22:2655-63. https://doi.org/10.1097/00007632-199711150-00014.

6. Akamaru T, Kawahara N, Tim Yoon S, Minamide A, Su Kim K, Tomita K, et al. Adjacent segment motion after a simulated lumbar fusion in different sagittal alignments: a biomechanical analysis. Spine (Phila Pa 1976). 2003:28:1560-6.

7. Srinivas GR, Kumar MN, Deb A. Adjacent disc stress following floating lumbar spine fusion: a finite element study. Asian Spine J. 2017;11:53847. https://doi.org/10.4184/asj.2017.11.4.538.

8. Pellet N, Aunoble S, Meyrat R, Rigal J, Le Huec JC. Sagittal balance parameters influence indications for lumbar disc arthroplasty or ALIF. Eur Spine J. 2011:20(Suppl 5):647-62. https://doi.org/10.1007/s00586-011-1933-0.

9. Barrey C, Roussouly P, Perrin G, Le Huec JC. Sagittal balance disorders in severe degenerative spine. Can we identify the compensatory mechanisms? Eur Spine J. 2011;20(Suppl 5):626-33. https://doi.org/10.1007/ s00586-011-1930-3.

10. Le Huec JC, Thompson W, Mohsinaly Y, Barrey C, Faundez A. Correction to: sagittal balance of the spine. Eur Spine J. 2019;28:2631. https://doi.org/10 1007/s00586-019-06128-5.

11. Rothenfluh DA, Mueller DA, Rothenfluh E, Min K. Pelvic incidence-lumbar lordosis mismatch predisposes to adjacent segment disease after lumbar spinal fusion. Eur Spine J. 2015;24:1251-8. https://doi.org/10.1007/ s00586-014-3454-0.

12. Farshad-Amacker NA, Hughes AP, Aichmair A, Herzog RJ, Farshad M. Determinants of evolution of endplate and disc degeneration in the lumbar spine: a multifactorial perspective. Eur Spine J. 2014;23:1863-8. https://doi.org/10.1007/s00586-014-3382-z.

13. Roussouly P, Pinheiro-Franco JL. Sagittal parameters of the spine: biomechanical approach. Eur Spine J. 2011;20(Suppl 5):578-85. https://doi.org/ 10.1007/s00586-011-1924-1.

14. Pfirrmann CW, Metzdorf A, Zanetti M, Hodler J, Boos N. Magnetic resonance classification of lumbar intervertebral disc degeneration. Spine (Phila Pa 1976). 2001;26:1873-8. https://doi.org/10.1097/00007632-20010 9010-00011.

15. Weishaupt D, Zanetti M, Boos N, Hodler J. MR imaging and CT in osteoarthritis of the lumbar facet joints. Skeletal Radiol. 1999;28:215-9. https:// doi.org/10.1007/s002560050503.

16. Delp SL, Anderson FC, Arnold AS, Loan P, Habib A, John CT, et al. OpenSim: open-source software to create and analyze dynamic simulations of movement. IEEE Trans Biomed Eng. 2007:54:1940-50. https://doi.org/10. 1109/TBME.2007.901024.

17. Senteler M, Weisse B, Snedeker JG, Rothenfluh DA. Pelvic incidence-lumbar lordosis mismatch results in increased segmental joint loads in the unfused and fused lumbar spine. Eur Spine J. 2014;23:1384-93. https:// doi.org/10.1007/s00586-013-3132-7.

18. Senteler M, Weisse B, Rothenfluh DA, Snedeker JG. Intervertebral reaction force prediction using an enhanced assembly of OpenSim models. 
Comput Methods Biomech Biomed Engin. 2016;19:538-48. https://doi. org/10.1080/10255842.2015.1043906.

19. Vialle R, Levassor N, Rillardon L, Templier A, Skalli W, Guigui P. Radiographic analysis of the sagittal alignment and balance of the spine in asymptomatic subjects. J Bone Joint Surg Am. 2005;87:260-7. https://doi. org/10.2106/JBJS.D.02043

20. Jiang S, Li W. Biomechanical study of proximal adjacent segment degeneration after posterior lumbar interbody fusion and fixation: a finite element analysis. J Orthop Surg Res. 2019;14:135. https://doi.org/10.1186/ s13018-019-1150-9.

21. Abode-lyamah K, Kim SB, Grosland N, Kumar R, Belirgen M, Lim TH, et al. Spinal motion and intradiscal pressure measurements before and after lumbar spine instrumentation with titanium or PEEK rods. J Clin Neurosci. 2014;21:651-5. https://doi.org/10.1016/j.jocn.2013.08.010.

22. Barbir A, Godburn KE, Michalek AJ, Lai A, Monsey RD, latridis JC. Effects of torsion on intervertebral disc gene expression and biomechanics, using a rat tail model. Spine (Phila Pa 1976). 2011;36:607-14. https://doi.org/10. 1097/BRS.0b013e3181d9b58b.

23. Kim J, Yang SJ, Kim H, Kim Y, Park JB, Dubose C, et al. Effect of shear force on intervertebral disc (IVD) degeneration: an in vivo rat study. Ann Biomed Eng. 2012;40:1996-2004. https://doi.org/10.1007/ s10439-012-0570-z.

24. Senteler M, Weisse B, Rothenfluh DA, Farshad MT, Snedeker JG. Fusion angle affects intervertebral adjacent spinal segment joint forces-Modelbased analysis of patient specific alignment. J Orthop Res. 2017:35:131-9. https://doi.org/10.1002/jor.23357.

25. Aiyangar AK, Zheng L, Tashman S, Anderst WJ, Zhang X. Capturing threedimensional in vivo lumbar intervertebral joint kinematics using dynamic stereo-X-ray imaging. J Biomech Eng. 2014;136:011004. https://doi.org/ 10.1115/1.4025793.

26. Ruberté LM, Natarajan RN, Andersson GB. Influence of single-level lumbar degenerative disc disease on the behavior of the adjacent segments--a finite element model study. J Biomech. 2009:42:341-8. https://doi.org/10. 1016/j.jbiomech.2008.11.024.

\section{Publisher's Note}

Springer Nature remains neutral with regard to jurisdictional claims in published maps and institutional affiliations.

- fast, convenient online submission

- thorough peer review by experienced researchers in your field

- rapid publication on acceptance

- support for research data, including large and complex data types

- gold Open Access which fosters wider collaboration and increased citations

- maximum visibility for your research: over 100M website views per year

At BMC, research is always in progress.

Learn more biomedcentral.com/submissions 